\title{
Endoscopic ultrasound (EUS)-guided coil embolization therapy in gastric varices
}

Bleeding from gastric varices is a lifethreatening event, however, there is no global consensus on its optimum treatment. Recently, the use of therapeutic endoscopic ultrasound (EUS) in vascular disorders has been reported [1-5]. Here we report on four patients with severe gastric varices (two patients with Child-Pugh class A, and one each with class B and C; two patients with bleeding) treated with EUS-guided coil embolization.

We informed all four patients and their relatives about the experimental nature of the technique and obtained written informed consent. Prophylactic antibiotic therapy was administered and the working channel of the endoscope was flushed with povidone-iodine before the procedure. Under EUS and fluoroscopy guidance, stainless steel, synthetic-fiber coils (MReye; IMWCE, Cook, Limerick, Ireland), of diameter 0.035 inch, straight length $50-150 \mathrm{~mm}$, and coiled diameter 8-15 mm, were deployed through a 19gauge needle ( Fig. 1, 2). Once the needle was inside the vessel, the stylet was withdrawn and the coil was deployed by advancing the stiffer part of a 0.035 inch guide wire, with the aim of delivering it as coiled as possible. In the first patient, who had a large gastrorenal shunt, we delivered the coils into the gastric varices to prevent migration. After we had placed 13 coils, neither migration nor thrombosis was observed. Therefore we modified the technique to deliver the coils not into the varix but into its perforating feeding vein, and nine additional coils were deployed in the first patient and seven ( $\bullet$ Video 1,2 ), three, and two coils were deployed in the remaining three patients. All the coils were delivered into the perforating feeding vein, with the aim of forming a mesh to block the flow of blood. The diameter of the perforating feeding vein in the four patients was $13 \mathrm{~mm}, 12 \mathrm{~mm}, 8 \mathrm{~mm}$, and 6 $\mathrm{mm}$. The coils were selected depending on their expected size once they were coiled, which was approximately $20 \%$ greater that the caliber of the perforating vessels. The gastric varices were eradicated in three of the four patients (75\%). No migration or complications were observed in these three patients on follow up at a mean of 5 months after the procedure

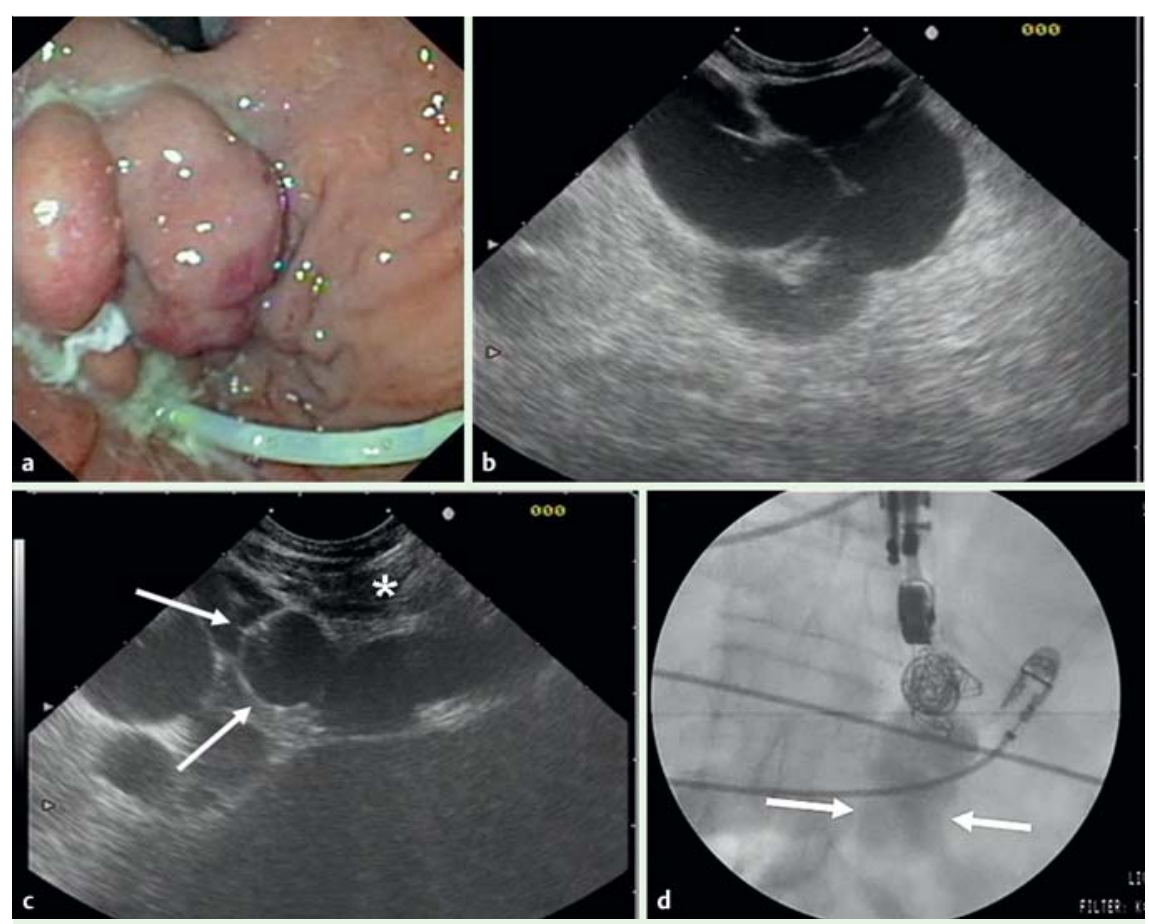

Fig. 1 a Endoscopic view of gastric varices in the second patient treated with endoscopic ultrasound (EUS)-guided coil embolization therapy. A nasogastric tube is also seen. $\mathbf{b}$ EUS view of the gastric varices. c EUS-guided coil (arrows) deployed in the perforating vein of the gastric varices. The 19-gauge needle is seen traversing the diaphragm (asterisk). $\mathbf{d}$ The delivered coils formed a thick mesh that blocked the blood flow through the perforating feeding vein of the gastric varices, with downstream flow of the contrast injected through the 19-gauge needle. Note the width of the column of dye (between white arrows) compared with the caliber of the therapeutic echoendoscope.

(range 1-13 months). Although (EUS)guided coil embolization therapy is a technically demanding procedure, our preliminary experience shows it can be carried out in less than 30 minutes. The overall mortality was $25 \%$, however, this

\section{Video 1}

Endoscopic ultrasound (EUS)-guided deployment of seven coils in the perforating vein of isolated fundal varices, resulting in complete thrombosis.

\section{Video 2}

Fluoroscopic image showing the deployment of the seventh coil. The injected contrast flows downstream (note the caliber of the vessel compared with the therapeutic echoendoscope). Both endoscopic and EUS procedures resulted in total thrombosis 1 week after the seven coils had been deployed. was not related to the procedure. Larger series are warranted to further evaluate this technique.

\section{Acknowledgments \\ $\nabla$}

The authors thank Ursula Feore and Leonor Zarza for reviewing the English text and all the workers at the Endoscopy Unit for their daily support.

Parts of the work in this report have been reported as an oral presentation at the EURO EUS meeting held in April 2008 in Milan, Italy, as a poster at the EUS 2008 meeting held in September 2008 in San Francisco, USA, and as an oral presentation at the EURO EUS meeting held in May 2009 in Berlin, Germany.

Endoscopy_UCTN_Code_TTT_1AS_2AB 

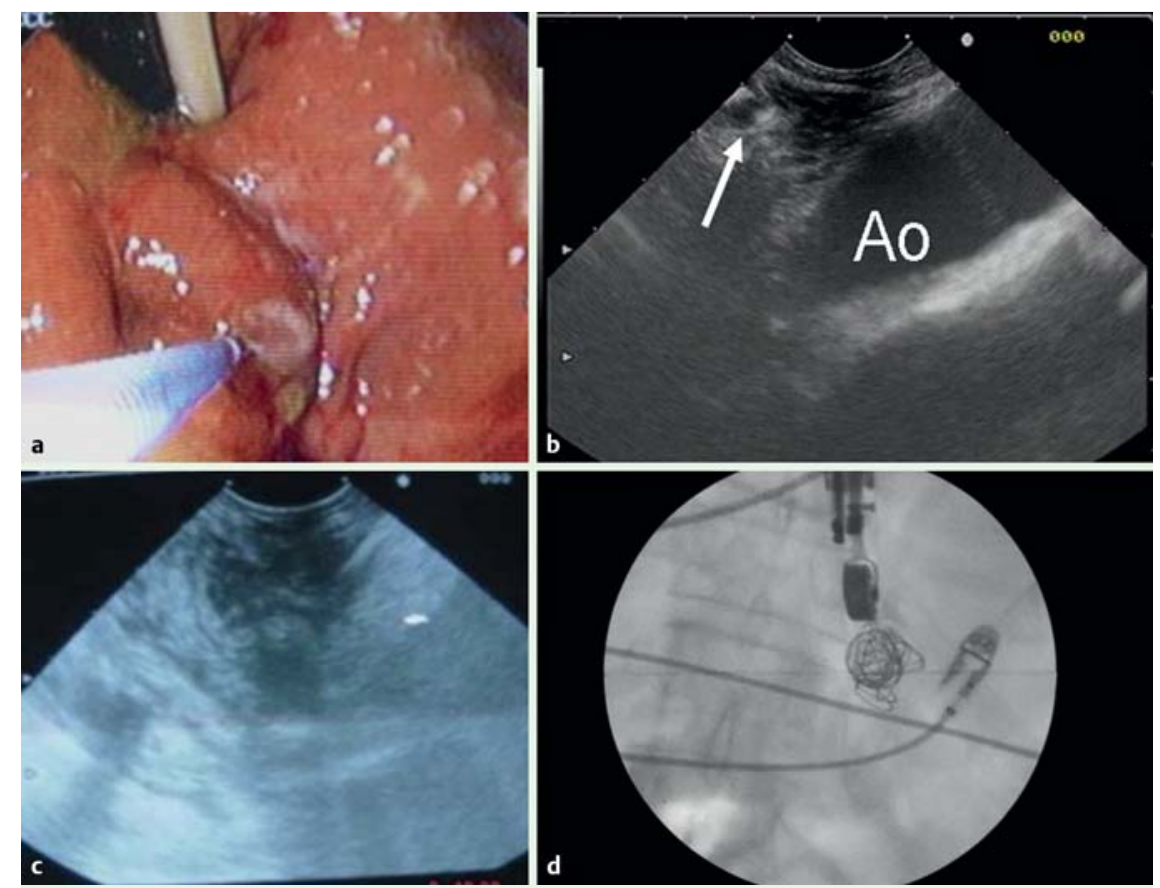

Fig. 2 a Gastric varices reduced to form firm folds on palpation. b Endoscopic ultrasound (EUS) examination showing a thrombosed perforating vein with coils (arrow). Ao, aorta. c EUS examination also showing a gastric wall without varices and with coils with an acoustic shadow. $\mathbf{d}$ The thick mesh formed by the seven deployed coils.

R. Romero-Castro ${ }^{1}$, F. Pellicer-Bautista ${ }^{1}$, M. Giovannini ${ }^{2}$, F. Marcos-Sánchez ${ }^{3}$,

C. Caparros-Escudero ${ }^{4}$, M. JiménezSáenz ${ }^{1}$, M. Gomez-Parra ${ }^{1}$, A. ArenzanaSeisdedos $^{5}$, V. Leria-Yebenes ${ }^{6}$, J. M. Herrerias-Gutiérrez ${ }^{1}$

1 Gastroenterology Service, Virgen Macarena Hospital, Seville, Spain

2 Endoscopy Unit, Paoli-Calmettes Institute, Marseilles, France
3 Department of Vascular Invasive Radiology, Virgen Macarena Hospital, Seville, Spain

4 Department of Radiology, Virgen Macarena Hospital, Seville, Spain

5 Intensive Care Unit, Virgen Macarena Hospital, Seville, Spain

6 Department of Anesthesiology, Virgen Macarena Hospital, Seville, Spain

\section{References}

1 Romero-Castro R, Pellicer-Bautista FJ, Jimenez-Saenz $M$ et al. EUS-guided injection of cyanoacrylate in perforating feeding veins in gastric varices: results in 5 cases. Gastrointest Endosc 2007; 66: $402-407$

2 Levy MJ, Wong Kee Song LM, Kendrick ML et al. EUS-guided coil embolization for refractory ectopic variceal bleeding. Gastrointest Endosc 2008; 67: 572-574

3 Fritscher-Ravens A, Ganbari A, Mosse CA et al. Transesophageal endoscopic ultrasoundguided access to the heart. Endoscopy 2007; 39: $385-389$

4 Romero-Castro R, Rios-Martin JJ, GallegoGarcia de Vinuesa $P$ et al. Pericardial tumor diagnosed by EUS-guided FNA (with video). Gastrointest Endosc 2009; 69: 562 - 563

5 Von Bartheld MB, Rabe KF, Annema JT. Transaortic EUS-guided FNA in the diagnosis of lung and lymph nodes. Gastrointest Endosc 2009; 69: 345 - 349

\section{Bibliography}

DOI $10.1055 / \mathrm{s}-0029-1215261$

Endoscopy 2010; 42: E35-E36

(c) Georg Thieme Verlag KG Stuttgart · New York . ISSN 0013-726X

\section{Corresponding author}

\section{R. Romero-Castro, MD, PhD}

Gastroenterology Service,

Virgen Macarena Hospital

Av. Dr. Fedriani 3

41009-Seville

Spain

Fax: +34-955-008805

romeror@medynet.com 